\title{
Micro X-ray Computed Tomography and Image Analysis of Frozen Potatoes Subjected to Freeze-Thaw Cycles
}

\author{
Ying Zhao ${ }^{1}$ and Pawan S. Takhar ${ }^{2}$
}

\begin{abstract}
Frozen products are subjected to freeze-thaw cycles during storage and shipping. These temperature fluctuations result in ice recrystallization, which causes undesirable quality changes, texture loss, and surface dehydration of frozen foods. The objective of this study was to investigate the effect of temperature fluctuations on ice crystal growth/decay in frozen potatoes. The potatoes, which were in a cuboid French fry shape, were frozen at $-80^{\circ} \mathrm{C}$ (control group) and fluctuated from -17 and $-16{ }^{\circ} \mathrm{C},-17$ and $-11{ }^{\circ} \mathrm{C}$, and -17 and $-7{ }^{\circ} \mathrm{C}$ for one and two weeks' duration. X-ray micro-computed tomography (CT) was used to observe the three-dimensional (3D) microstructure of frozen potatoes. Image analysis showed significant growth of ice crystals with increases in temperature fluctuations and duration of freezing. The total number of pores was reduced with increases in amplitude and duration of freeze-thaw cycles. These results demonstrate that micro-CT and image analysis can be used to analyze the microstructure of frozen materials and obtain valuable information for designing the freezing process.
\end{abstract}




\section{Introduction}

23 Freezing is one of the most important methods to extend the shelf life of foods. The freezing

24 process can prevent microbial growth, reduce water availability, and decrease chemical and

25 enzymatic reaction rates (Sun, 2016). Freezing is initiated by nucleation when the external

26 temperature falls below the food's freezing point. Ice crystals start to grow and propagate as the

27 temperature falls, and the solute concentration gradually increases in unfrozen regions as the

28 vicinal water diffuses to the nucleation sites to crystallize. When the freezing temperature drops

29 enough, and the maximum freeze concentration of solutes is reached, a non-equilibrium but

30 highly viscous glassy state dominates the freezing process, and the corresponding temperature is

31 defined as glass transition temperature $\left(\mathrm{T}_{\mathrm{g}}{ }^{\prime}\right)$. In the glassy state, the mobility of water and other

32 molecules decreases significantly due to the high viscosity $\left(\sim 10^{13}\right.$ poise $)$ and low temperature

33 during freezing. Therefore, a frozen product that remains in the glassy state is considered to be in

34 the ideal storage condition.

35 The potato is the $4^{\text {th }}$ most important global food crop after rice, wheat, and maize. More than $30 \%$

36 of the potato crop is processed as French fries worldwide (Saguy, 1995). For longer and more

37 stable storage, raw French fries are usually frozen to avoid discoloration and blackheart in the

38 tissues (Talburt \& Smith, 1967). However, during the shipping and storage of frozen foods,

39 damage to product quality may occur due to temperature fluctuations. These freeze-thaw cycles

40 may result in textural changes, moisture migration, and ice recrystallization in the frozen

41 materials (Adapa, Schmidt, Jeon, Herald, \& Flores, 2000). The rate of ice crystal growth, the

42 surface area, and the volume of pores in potatoes significantly increase as a function of

43 temperature fluctuations during the freezing process (Szymońska \& Wodnicka, 2005). Freezing

44 and thawing would also annul the positive effects, such as inducing small ice crystals and 
45 keeping foods in the glassy state, that prevail during quick freezing. Food components may

46 undergo a transition from a glassy to rubbery state or even defrost because of temperature

47 instability. Some ice may also melt, which leads to a gradual growth of the mean crystal size

48 caused by accretive and migratory recrystallization. The intracellular and intercellular diffusion

49 rate of water increases dramatically, which is caused by not only the glassy-to-rubbery state

50 transition, but also the dilution occurring from the melting of small ice crystals. As a result, the

51 moisture in the frozen product is lost and the microstructure of solid walls is damaged (Goff,

52 1997). Therefore, the temperature fluctuations that occur during the freezing process and storage

53 cause critical damage to frozen foods through quality degradation.

54 To improve shipping and storage conditions of frozen foods as well as to solve heat and fluid

55 transport models for designing freezing systems, there is a need to investigate ice crystal growth

56 and distribution in frozen food products. X-ray micro-computed tomography (CT) provides high-

57 resolution internal imaging of materials. It allows visualization and measurement of the complete

58 three-dimensional morphological configuration of objects without invasion. This technique is

59 broadly applied in the investigation of rocks, bones and metals (Salvo, Cloetens, Maire, Zabler,

60 Blandin, Buffière, \& Josserond, 2003; Buffiere, Maire, Adrien, Masse, \& Boller, 2010). In

61 addition, food materials such as fresh fruits, beef, and food proteins have been imaged with

62 micro-CT to determine their microstructures and other physical characteristics (Frisullo, Marino,

63 Laverse, Albenzio, \& Del Nobile, 2010; Mousavi, Miri, Cox, \& Fryer, 2007; Ta-Te Lin et al.,

64 2008). Ullah et al. (2014) performed a 2D image analysis for freeze-dried potatoes scanned with

65 micro-CT and investigated the ice morphology and pore size distribution. 3D image analysis was

66 used in the present study, which provides a direct observation of the whole structure of frozen

67 samples. Alam and Takhar (2016) also conducted micro-CT scanning of fried potatoes and used 
Avizo 9.0 (FEI Houston, Hillsboro, OR, U.S.A) for image analysis by selecting the pores using manual thresholding based upon visual judgment.

The objective of this study was to quantify the 3D ice crystal morphology, size distribution, and volume fraction by performing micro X-ray computed tomography of frozen potatoes, which are

72 subjected to simulated temperature fluctuations encountered during industrial storage and

73 shipping. An image analysis was carried out by utilizing "auto-thresholding" and "watershed

74 separation" methods implemented in commercial 3D image analysis software (Avizo 9.0, FEI

75 Visualization Sciences Group, Hillsboro, OR, U.S.A). Using these methods allowed for

76 performing objective segmentation and reduced strenuous analysis steps of manual segmentation,

77 as employed in the study of Alam and Takhar (2016) for fried potato disks.

2. Materials and methods

\section{Sample preparation and freezing method}

81 Fresh potatoes of the Russet variety were purchased from a local grocery store. Potatoes of

82 similar size were selected and cut into cuboidal (11.9 mm side) fries. The cut potatoes were

83 blanched at about $85^{\circ} \mathrm{C}$ for two minutes to remove starch from the surface and prevent browning

84 from contact with atmospheric oxygen. The cut samples were divided into seven groups and put

85 in Ziploc storage bags marked from S1 to S7 for further freeze processing. Each group contained

86 about ten cuboidal potatoes. One group of samples (S1) was stored in a freezer at $-80{ }^{\circ} \mathrm{C}$ and

87 designated the control. Other groups were stored in the freezer at varying temperatures. Sample

88 groups S2 and S3 experienced a temperature fluctuation between $-17^{\circ} \mathrm{C}$ and $-16{ }^{\circ} \mathrm{C}$ for one and

89 two weeks, respectively. Sample groups S4 and S5 were placed in the freezer with temperatures 
90 fluctuating between $-17{ }^{\circ} \mathrm{C}$ and $-11{ }^{\circ} \mathrm{C}$ for one and two weeks, respectively. $\mathrm{S} 6$ and $\mathrm{S} 7$ were put

91 in the freezer with temperatures varying between $-17^{\circ} \mathrm{C}$ and $-7^{\circ} \mathrm{C}$ for one and two weeks,

92 respectively. Ullah et al. (2014) followed the procedure detailed in Syamaladevi et al. (2010) to

93 determine that onset of ice melting at maximum freeze-concentration occurs at $\left(\mathrm{T}_{\mathrm{m}}{ }^{\prime}\right)$ of $-13{ }^{\circ} \mathrm{C}$

94 for frozen potatoes. Therefore, the first range of temperature fluctuations $\left(-17\right.$ to $\left.-16{ }^{\circ} \mathrm{C}\right)$ was

95 selected with minimum variation below $\mathrm{T}_{\mathrm{m}}$ '. The second and third ranges of fluctuating

96 temperature amplitudes $\left(-17\right.$ to $-11^{\circ} \mathrm{C}$ and -17 to $\left.-7^{\circ} \mathrm{C}\right)$ were kept around $\mathrm{T}_{\mathrm{m}}$, which were

97 expected to yield larger crystals then fluctuation amplitudes below Tm'. The temperature of the

98 freezers during storage was regulated by a programmable temperature controller (Model BCS-

99 462, Embedded Control Concepts, Huntington Beach, CA). The temperature fluctuations were

100 performed for one and two weeks. One freeze-thaw cycle took about 20 to 24 hours to complete.

101 Thermocouples were placed in the middle of the plastic bags and freezer to record temperature

102 profiles and monitor the operation of the freezer.

\section{X-ray micro-CT imaging}

104 After freezing, the samples were dehydrated using a vacuum freeze dryer (FreeZone 6, Labconco

105 Co., Kansas City, MO) for 48 hours. Freeze drying removed moisture inside the material by

106 sublimation and left a network of solid fibers and pores. The freeze-dried samples were scanned

107 by a high-performance X-ray computed tomography (CT) scanner (Model Micro XCT-400

108 Xradia, Rockville, CA) at the University of Illinois, Urbana-Champaign, IL, U.S.A. The scanner

109 settings used for obtaining the images were $1 \times$ magnification, $50 \mathrm{kV}$ voltage, and $10 \mathrm{~W}$ power

110 source. The exposure time was $2 \mathrm{~s}$ per slice, and the sample was rotated from $-180^{\circ}$ to $180^{\circ}$,

111 which resulted in 721 image slices for each sample. The total scanning time was about 90

112 minutes. Multiple replications for scanning each sample were not performed since micro-CT is 
113 an expensive technique. A voxel size of $22 \mu \mathrm{m}$ was used for image acquisition. The obtained

114 images (16-bit TIFF) were reconstructed into a series of 2D images using the XMReconstructor

115 software (Xradia Software, Xradia Inc., Pleasanton, CA).

\section{Image processing and analysis}

117 Figure 1 shows the image analysis steps performed using Avizo 9.0 (FEI Visualization Sciences

118 Group, Hillsboro, OR). First, the original image slices obtained from micro-CT scanning were

119 masked to remove the background (Figures $2 \mathrm{a}$ and $\mathrm{b}$ ). Then the contrast and brightness of the

120 images were adjusted to obtain a clear distinction between the pores and solids in the frozen

121 samples (Figure 2c). The auto-thresholding module of Avizo was used to compute a two-level

122 threshold of the grayscale images. The frozen potatoes subjected to a temperature fluctuation

123 from -17 to $-7^{\circ} \mathrm{C}(\mathrm{S} 7)$ are presented as an example to describe the image processing steps. Two

124 intensity values of 5201 and 20805 were obtained for sample S7 using auto-thresholding in

125 Avizo. These two intensity values marked pores and solids respectively in the S7 images. These

126 intensity values served as reference values for further segmentation (Figure 2d). Pores inside the

127 samples were selected by inputting the first intensity level (0-5201). After this selection, the

128 pixels inside the first intensity level were highlighted and assigned a value of 1 . Thus, the

129 grayscale images were transformed into binary images (Figure 2e). Next, some noise filtering

130 was applied to remove small islands and fill 3D cavities less than 15 pixels in size. This noise

131 filtering did not affect the porous and solid regions of the image. Watershed segmentation was

132 used to improve porous and solid regions marked using auto-thresholding (Haris, Efstratiadis,

133 Maglaveras, \& Katsaggelos, 1998). The watershed algorithm is analogous to the water drops,

134 which follow a distance map to separate a landscape into different catchment basins (Orbert,

135 Bengtsson, \& Nordin, 1993). The "separate objects" feature of Avizo 9.0 was used to compute 
watershed lines on a distance map. This allowed for separation of the connected pores to obtain the distribution of sizes (Figure 2f). If this separation is not performed, all connected pores appear as one large pore, which does not yield pore size distribution. Label analysis was performed to obtain the volume distribution of pores. The equivalent pore diameter $\left(D_{e q}\right)$ values were calculated from the volume of pores $\left(V_{3 D}\right)$ using the following equation:

$$
D_{e q}=\sqrt[3]{\frac{6^{*} V_{3 D}}{\pi}}
$$

Pore size distribution was depicted by plotting a histogram of the label analysis results. Solid walls were also segmented with a similar method, using the second intensity level 5201-20805 obtained using auto-thresholding (Figure 2g). A 3D view of the solid fraction was rendered for direct visualization of the inner microstructure of samples (Figure $2 \mathrm{~h}$ ).

Porous properties, such as the number of pores, equivalent diameter, pore volume, and pore size distribution were analyzed using Origin Pro (Ver 9.1, OriginLab Corp., Northamption, MA). A Shapiro-Wilk test was conducted to test the normality of pore size distribution using $\mathrm{R}(3.2 .2, \mathrm{R}$ Core Team., Vienna, Austria). Porosity $(\phi)$ of various samples was calculated as: $\varnothing=$ $V_{\text {pore }} / V_{\text {total }}$. Here, $V_{\text {pore }}$ represents the total volume of pores, and $V_{\text {total }}$ represents the total volume of a sample. Tortuosity was obtained using the centroid path tortuosity method, which computes the ratio of the length of a flow channel connecting two pores to the straight line distance between the two pores (Shanti, Chan, Stock, De Carlo, Tornton \& Faber, 2014).

\section{Results and discussion}


156 During rapid freezing at $-80{ }^{\circ} \mathrm{C}$, small crystals are formed, and solid walls in potatoes are

157 expected to be closer to their native structure (Ullah, Takhar, \& Sablani, 2014).

158 By comparing the pore sizes of the control sample (frozen at $-80{ }^{\circ} \mathrm{C}$ ) and samples subjected to

159 freeze-thaw cycles, deductions about crystal growth were made. Therefore, the micro-CT images

160 of samples subjected to freeze-thaw cycles can be analyzed to determine changes in pore size

161 distribution and their relationship to ice crystal sizes. These properties are needed to simulate

162 heat and fluid transport phenomena and to improve frozen product quality during shipment and

163 storage.

164 Pore counts and pore size distribution

165 Figure 3 depicts the 2D images (xy and xz plane) and 3D rendering for all of the micro-CT

166 scanned samples. The raw potatoes consisted of numerous interconnected micropores (Alam and

167 Takhar 2016). After freezing at $-80^{\circ} \mathrm{C}$, both $2 \mathrm{D}$ and $3 \mathrm{D}$ views show small compact pores, which

168 are either natively present in raw potatoes or were formed by very small ice crystals due to rapid

169 freezing, as the $-80^{\circ} \mathrm{C}$ water and solute molecules are expected to have limited mobility.

170 However, the ice crystals become larger when the amplitude of temperature fluctuation and

171 freezing time increase (Figure $3 \mathrm{~S} 2$ to S7). This can be explained by ice recrystallization

172 occurring during the freeze-thaw cycles. Recrystallization is caused by the diffusion of unfrozen

173 water in potato tissue to the crystal sites. Especially when the freezing temperature is not stable,

174 some smaller ice crystals melt and move to the surface of larger crystals to minimize free energy,

175 which leads to a gradual growth of mean crystal size in a sample. As the temperature fluctuations,

176 peak temperature value, and freezing time increase, the ice crystals are enlarged by the

177 intensified effect of recrystallization. The solid wall is also disrupted when the smaller ice

178 crystals migrate to the larger ones, which facilitates mass and moisture loss during freezing and 
179 degrades the product quality. A reduction in the number of ice crystals is also observed due to 180 the merger of smaller crystals to larger crystals when the fluctuations in temperature increase

181 (Figure 4). In the control sample (S1), the total number of pores was counted as 10,549 and a 182 thick fibrous network was observed in the 2D and 3D views. For samples (S2 and S3) obtained 183 by fluctuating temperature between -17 and $-16^{\circ} \mathrm{C}$ for one and two weeks, the total number of 184 pores were 3,932 and 3,848 respectively. This occurred due to an increase in ice crystal size, 185 which ruptured the walls of smaller pores. Even fewer pores were observed when the samples 186 (S4 and S5) were stored at a fluctuating temperature between -17 and $-11{ }^{\circ} \mathrm{C}$ for one week $187(\mathrm{~N}=3074)$ and two weeks $(\mathrm{N}=2216)$. Finally, at the temperature fluctuation between -17 and $1887^{\circ} \mathrm{C}$, only 1,275 and 851 pores remained in samples S6 and S7 respectively. The average pore 189 volumes are also shown in Figure 4. The average pore size becomes larger as the temperature 190 fluctuations and freezing time increase. This phenomenon is also observed in the 2D and 3D 191 views of samples (Figure 3). Smaller crystals were formed when the control group (S1) was 192 stored in a $-80{ }^{\circ} \mathrm{C}$ freezer because of the low and stable freezing temperature. The pore volume 193 increased as a result of solid structure disruption due to ice migration from smaller crystals to 194 larger ones. The results quantitatively indicate that the freeze-thaw cycles facilitate ice 195 recrystallization and disrupt product structure due to the growth of ice crystals.

196 Ullah et al. (2014) performed a 2D image analysis of the microstructure of potatoes subjected to 197 different temperature fluctuation ranges. Table 1 and Figure 5 present the comparison of the 198 equivalent diameter of pores and ice crystal growth in Ullah's study and the present results. 199 Different image processing methods are attributed to the difference in the pore diameter values. 200 We determined the equivalent diameter by selecting the pores using 3D image analysis and 201 equating pore volumes to equivalent sphere volumes, while Ullah et al. (2014) analyzed the 2D 
202 pore area and obtained diameter values from micro-CT images. Our results show a trend similar

203 to that of Ullah et al. (2014) -- when the amplitude of temperature fluctuations increases, ice

204 crystals become larger in size. Ice crystal growth percentage was determined using the following

205 equation:

206

$$
\% \text { Ice crystal growth }=\frac{\left(\text { Final } \mathrm{X}_{50}-\text { Initial } \mathrm{X}_{50}\right)}{{\text { Initial } \mathrm{X}_{50}}_{\mathrm{X}}} 100
$$

207 where $\mathrm{X}_{50}$ represents the median equivalent diameter of ice crystals and the initial $\mathrm{X}_{50}$ is the 208 equivalent diameter of the control sample (S1), which is assumed to be equal to the native pore 209 diameter in raw potato samples. The ice crystal growth rate confirmed that both temperature 210 fluctuations and freezing time duration accelerate crystal growth. The amplitude of temperature 211 fluctuations seemed to have a stronger effect on the growth rate in comparison to the increase in 212 freezing time (Figure 6). The crystal growth also represents the rate of recrystallization, which is 213 not only correlated with the molecular mobility of water and solute molecules, but also depends 214 on the difference between surrounding temperature and $\mathrm{T}_{\mathrm{g}}$ ' $\left(\mathrm{T}-\mathrm{T}_{\mathrm{g}}{ }^{\prime}\right)$ (Syamaladevi, Manahiloh, 215 Muhunthan, \& Sablani, 2012). Ice crystals in the glassy state $\left(\mathrm{T}<\mathrm{T}_{\mathrm{g}}{ }^{\prime}\right)$ have relatively smaller 216 size due to the limited molecular diffusivity compared to the rubbery state. The increased 217 temperature fluctuations aggravate the ice crystal growth and enlarge the pore volume, which 218 damages the solid walls and degrades the product quality. Similar observations have also been 219 reported for other frozen materials (Ablett, Clarke, Izzard, \& Martin, 2002; Do, Sagara, Tabata, 220 Kudoh, \& Higuchi, 2004; Syamaladevi Manahiloh, Muhunthan, Sablani, 2012).

221 Figures 7a-g show the quantitative analysis of pore size distribution for all samples. The 222 histograms present the non-normality in distributions, which was confirmed by performing a 223 Shapiro-Wilk test $(\mathrm{p}<0.001)$ using R (R Foundation, 2016). The possible reason for non- 
224 normality is the resolution limit of the X-ray micro-CT scanner. The voxel size for these tests

225 was $22 \mu \mathrm{m}$, which means that pores smaller than $22 \mu \mathrm{m}$ could not be quantified using image

226 analysis. Therefore, the average pore volumes exhibit the distributions with right-sided skewness.

227 The pore volume for the control group ranges between 0 and $4 \mathrm{~mm}^{3}$. The distributions clearly

228 show a broader distribution (b-g) as the temperature fluctuation and freezing time increase,

229 which spreads the range toward $10 \mathrm{~mm}^{3}$ when the sample was frozen between -17 to $7^{\circ} \mathrm{C}$ for

230 two weeks. In addition, the count of pore numbers shows a remarkably decreasing trend as the

231 pore volume increased.

\section{Label analysis and porous characterization}

233 Label analysis results also indicate a considerable difference in pore connection as a function of

234 temperature fluctuations and freezing time. In Figure 8, connected sets of pores are labeled with

235 the same color. The control group (S1) shows more connections between pores (Figure 8a),

236 which confirms the observation that raw potatoes have compact and interconnected pores. More

237 disruption of solid networks with increasing temperature fluctuations leads to fewer connections

238 between the voids and enlarges the volume of pores. Therefore, smaller pores melt and merge

239 together to form larger pores (Figures $8 b$ \& c). Figure 8 elucidates that small ice crystals merge

240 to form larger ones because of ice recrystallization.

241 The porosity of samples obtained with increase in freeze-thaw fluctuations (S2-S7) shows larger

242 magnitude than that of the control group, which indicates that freezing and thawing cycles

243 enlarge the size and volume of ice crystals. Tortuosity is the ratio of path length to the shortest

244 distance between connected pores and is a measure of the degree of waviness of connected pore

245 pathways. Figure 9 presents porosity and tortuosity of frozen samples as a function of the

246 increase in amplitude and duration of temperature fluctuations. A higher tortuosity value implies 
247 a greater resistance of the sinuous pore network to fluid flow (Vallabh, Banks-Lee, \& Seyam,

248 2010). Figure 9 shows that tortuosity decreases as porosity increases. The possible reason is that

249 wall disruption caused by the growth of ice crystals simplifies porous pathways' waviness. The

250 increase in porosity corresponds to the increase in freeze-thaw temperature fluctuations and

251 storage time duration.

252 From the image analysis results, it can be concluded that the temperature fluctuations during

253 freezing, storage, and transportation are expected to disrupt the microstructure of frozen potatoes

254 depending upon the temperature magnitude in comparison to $\mathrm{T}_{\mathrm{g}}$, as well as the amplitude and

255 duration of fluctuations.

4. Conclusion

258 The X-ray micro-computed tomography and analysis of acquired images offers valuable results

259 to show pores formed by ice crystals during freeze-thaw cycles. The 2D and 3D image analyses

260 clearly indicated that the size of ice crystals is influenced by the amplitude and duration of

261 temperature fluctuations. The increase in crystal size due to temperature fluctuations and

262 freezing time is caused by ice recrystallization during the freezing process. The ice crystals

263 continuously grow as the amplitude of temperature fluctuations increases, while the number of

264 pores left by ice crystals decreases as the smaller crystals merge and migrate to the larger ones.

265 As a result, solid walls and cell structures are ruptured, which influences the moisture/solute

266 diffusion and subsequently degrades frozen food quality. The detailed quantitative information

267 obtained from micro-CT image analysis can be used for modeling and designing transport

268 phenomena of freeze-thaw processes and improving textural attributes of frozen products. 


\section{Acknowledgements}

270 Thanks to USDA-NIFA for providing financial support under Award No. 2015-67017-23074.

271

272 


\section{Reference}

Ablett, S., Clarke, C. J., Izzard, M. J., \& Martin, D. R. (2002). Relationship between ice recrystallisation rates and the glass transition in frozen sugar solutions. Journal of the Science of Food and Agriculture, 82(15), 1855-1859.

Adapa, S., Schmidt, K. A., Jeon, I. J., Herald, T. J., \& Flores, R. A. (2000). Mechanisms of ice crystallization and recrystallization in ice cream: a review. Food Reviews International, 16(3), 259-271.

Alam, T., \& Takhar, P. S. (2016). Microstructural Characterization of Fried Potato Disks Using X-Ray Micro Computed Tomography. Journal of Food Science, 81(3), E651-E664.

Buffiere, J.-Y., Maire, E., Adrien, J., Masse, J.-P., \& Boller, E. (2010). In Situ Experiments with $\mathrm{X}$ ray Tomography: an Attractive Tool for Experimental Mechanics. Experimental Mechanics, 50(3), 289-305.

Do, G.-S., Sagara, Y., Tabata, M., Kudoh, K., \& Higuchi, T. (2004). Three-dimensional measurement of ice crystals in frozen beef with a micro-slicer image processing system. International Journal of Refrigeration, 27(2), 184-190.

Frisullo, P., Marino, R., Laverse, J., Albenzio, M., \& Del Nobile, M. A. (2010). Assessment of intramuscular fat level and distribution in beef muscles using X-ray microcomputed tomography. Meat Science, 85(2), 250-255.

Goff, H. D. (1997). Measurement and Interpretation of the Glass Transition in Frozen Foods. In Quality in Frozen Foods (pp. 29-50). Boston, MA: Springer US.

Haris, K., Efstratiadis, S. N., Maglaveras, N., \& Katsaggelos, A. K. (1998). Hybrid image segmentation using watersheds and fast region merging. IEEE Transactions on Image Processing, 7(12), 1684-1699.

Mousavi, R., Miri, T., Cox, P. W., \& Fryer, P. J. (2007). Imaging food freezing using X-ray microtomography. International Journal of Food Science \& Technology, 42(6), 714-727.

Orbert, C. L., Bengtsson, E. W., \& Nordin, B. G. (1993). Watershed segmentation of binary images using distance transformations. International Society for Optics and Photonics, pp.159-170

Saguy, I. S. (1995). Oil uptake during deep-fat frying: factors and mechanism. Food Technology, 49(4), 142-145.

Salvo, L., Cloetens, P., Maire, E., Zabler, S., Blandin, J. ., Buffière, J. ., ... Josserond, C. (2003). $\mathrm{X}$-ray micro-tomography an attractive characterisation technique in materials science. Nuclear Instruments and Methods in Physics Research Section B: Beam Interactions with Materials and Atoms, 200, 273-286. 
Shanti, N. O., Chan, V. W. L., Stock, S. R., De Carlo, F., Thornton, K., \& Faber, K. T. (2014). $\mathrm{X}$-ray micro-computed tomography and tortuosity calculations of percolating pore networks. Acta Materialia, 71, 126-135.

Sun, D. (2016). Handbook of frozen food processing and packaging. London, CRC press.

Syamaladevi, R. M., Manahiloh, K. N., Muhunthan, B., \& Sablani, S. S. (2012). Understanding the Influence of State/Phase Transitions on Ice Recrystallization in Atlantic Salmon (Salmo salar) During Frozen Storage. Food Biophysics, 7(1), 57-71.

Syamaladevi, R. M., Sablani, S. S., Tang, J., Powers, J., \& Swanson, B. G. (2010). Water sorption and glass transition temperatures in red raspberry (Rubus idaeus). Thermochimica Acta, 503, 90-96.

Szymońska, J., \& Wodnicka, K. (2005). Effect of multiple freezing and thawing on the surface and functional properties of granular potato starch. Food Hydrocolloids, 19(4), 753-760.

Talburt, W., \& Smith, O. (1967). Potato processing. Westport, Conn., USA,

Ta-Te Lin, T.-T., Yung-Chen Liao, Y.-C., Tze-Wei Huang, T.-W., Cheng-Shiou Ouyang, C.-S., Joe-Air Jiang, J.-A., Man-Miao Yang, M.-M., \& En-Cheng Yang, E.-C. (2008). X-ray Computed Tomography Analysis of Internal Injuries of Selected Fruits. In 2008 Providence, Rhode Island, June 29 - July 2, 2008 (p. 1). St. Joseph, MI: American Society of Agricultural and Biological Engineers.

Ullah, J., Takhar, P. S., \& Sablani, S. S. (2014). Effect of temperature fluctuations on ice-crystal growth in frozen potatoes during storage. LWT - Food Science and Technology, 59(2), 1186-1190.

Vallabh, R., Banks-Lee, P., \& Seyam, A. (2010). New approach for determining tortuosity in fibrous porous media. Journal of Engineered Fibers, 5(3), 7-19. 


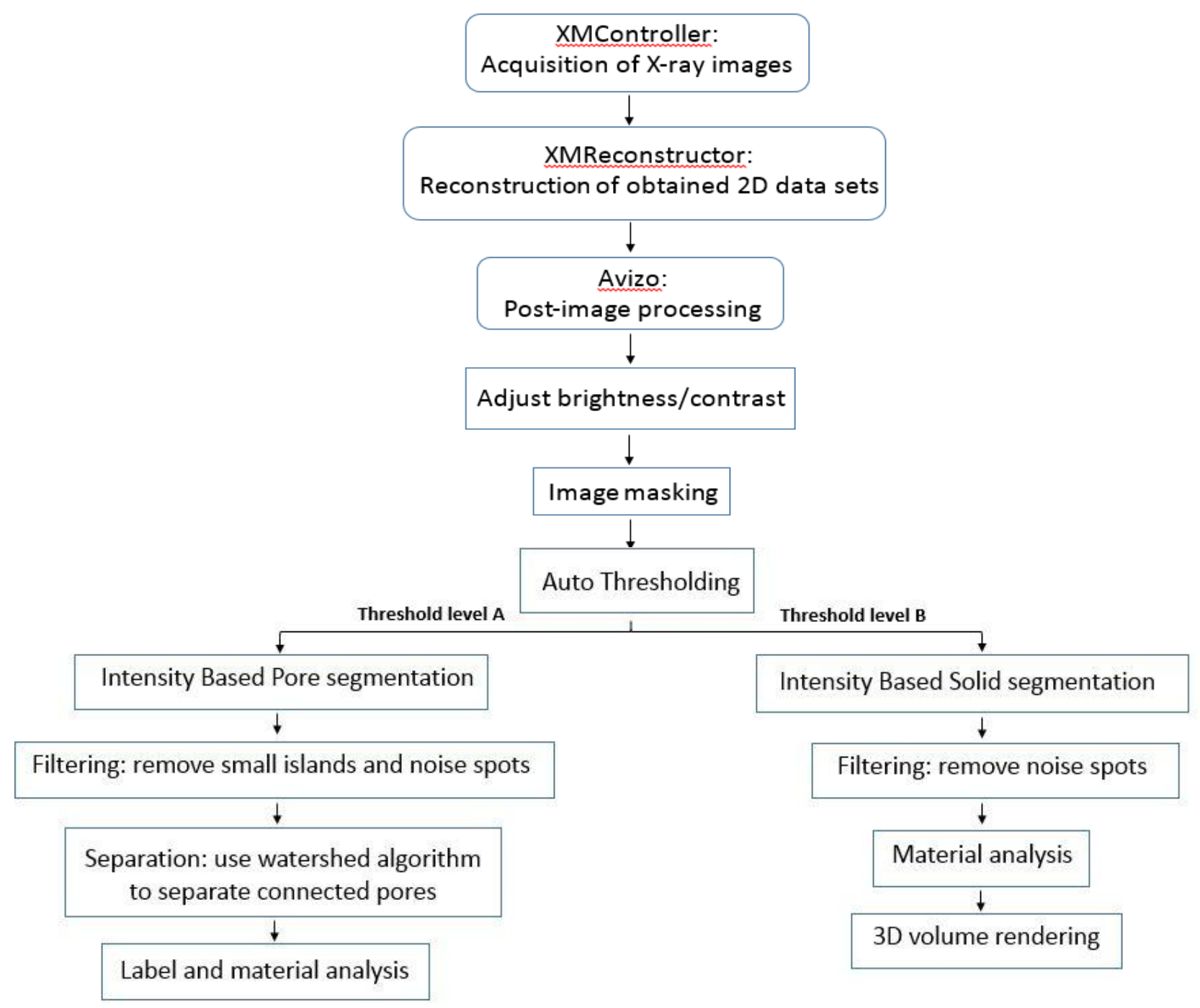

Figure 1 The flow chart depicting image processing and analysis steps. 

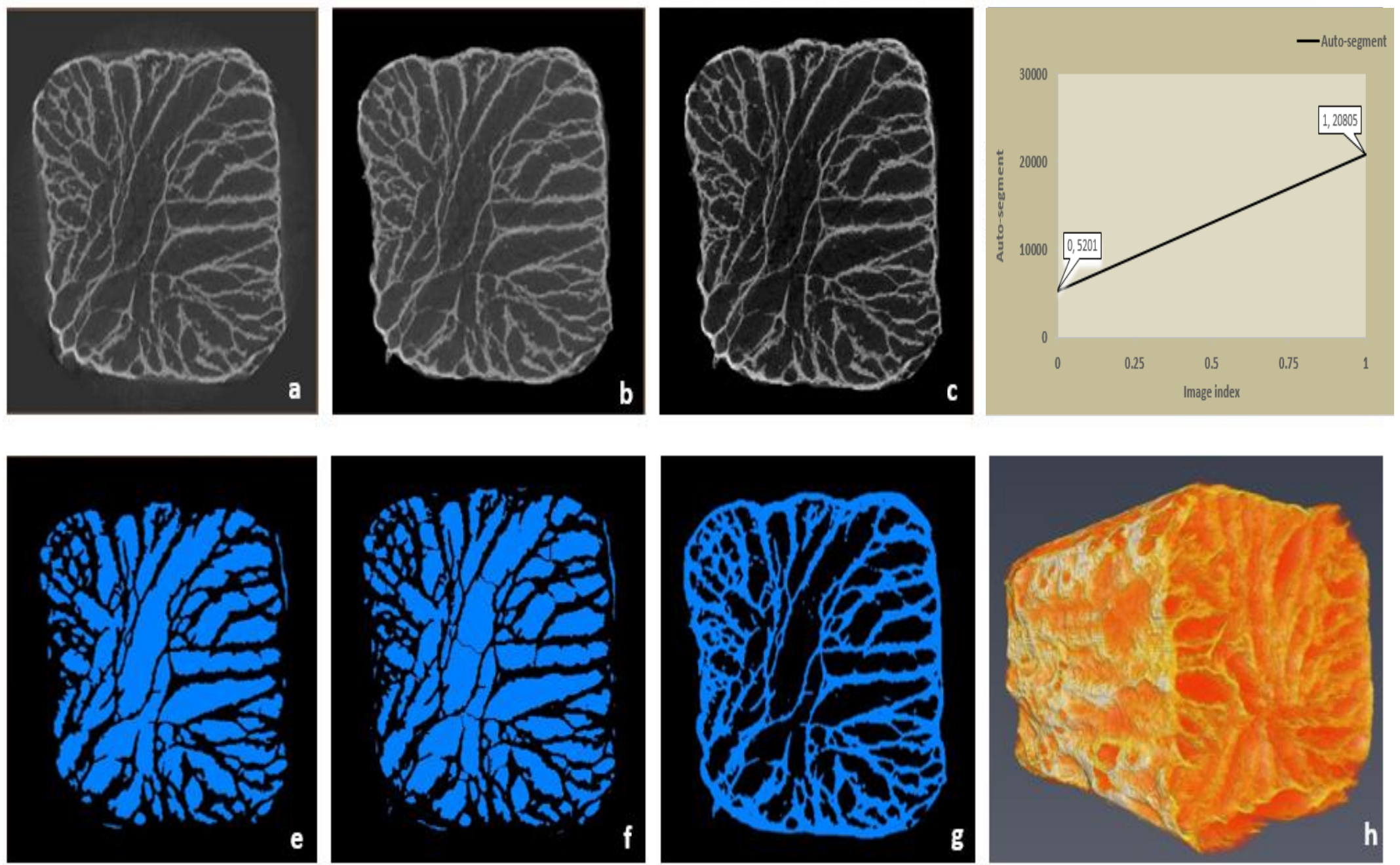

Figure 2 Image processing steps of micro X-ray CT data of a frozen potato (S7). a) Grayscale image orthoslice. b) Image masking. c) Contrast and brightness adjustment. d) Auto-thresholding (the phases' thresholding intensities are 5201 and 20805). e) Segmentation of pores by using the thresholding intensity range from 0-5201. f) Separation objects using the watershed algorithm. g) Segmentation of the solids using the thresholding intensity range from 5201-20805. h) 3D rendering of solid structure. 
$-80^{\circ} \mathrm{C}$

(S1)
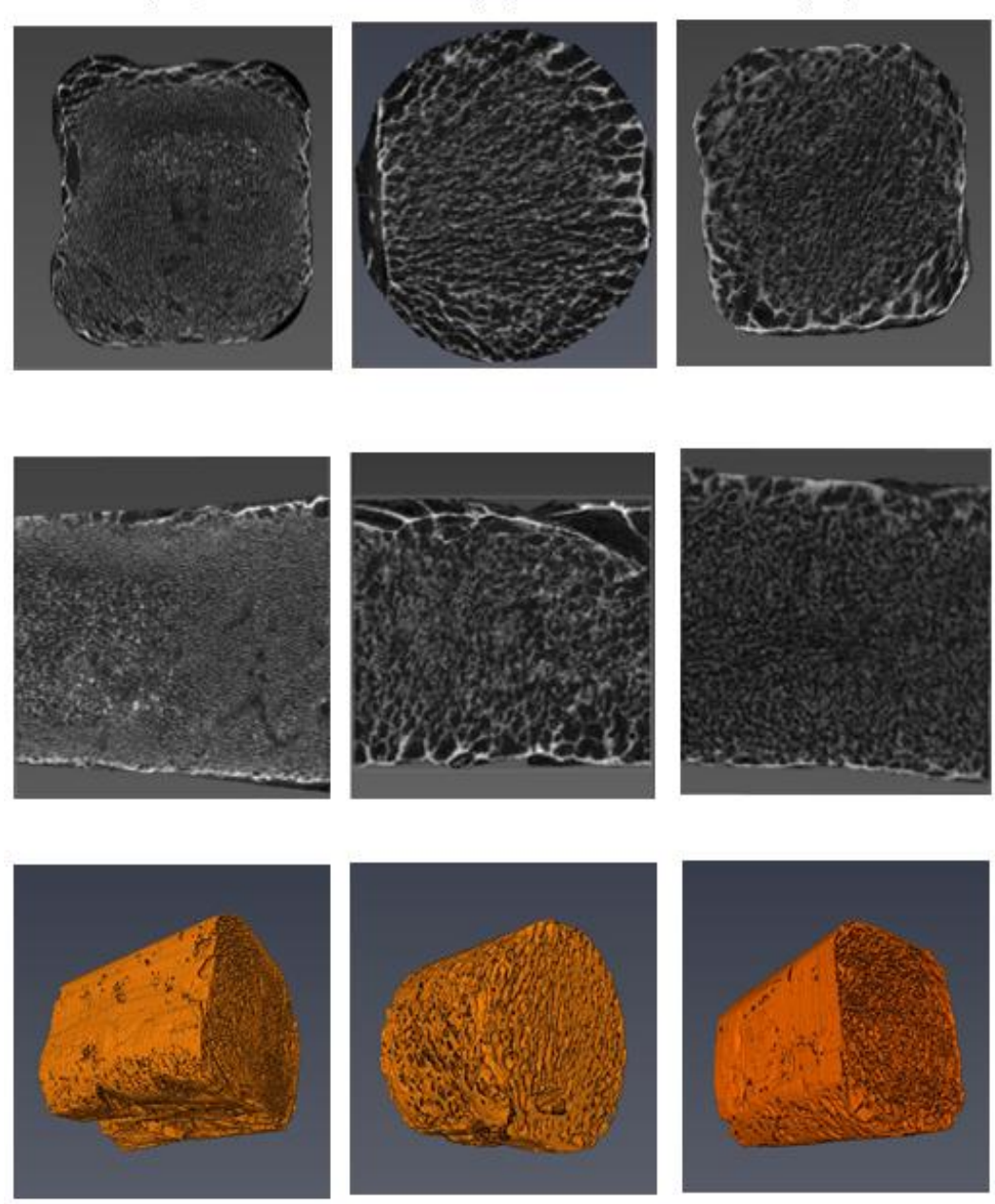

-17 to $-11^{\circ} \mathrm{C} 1$ week

(S4)
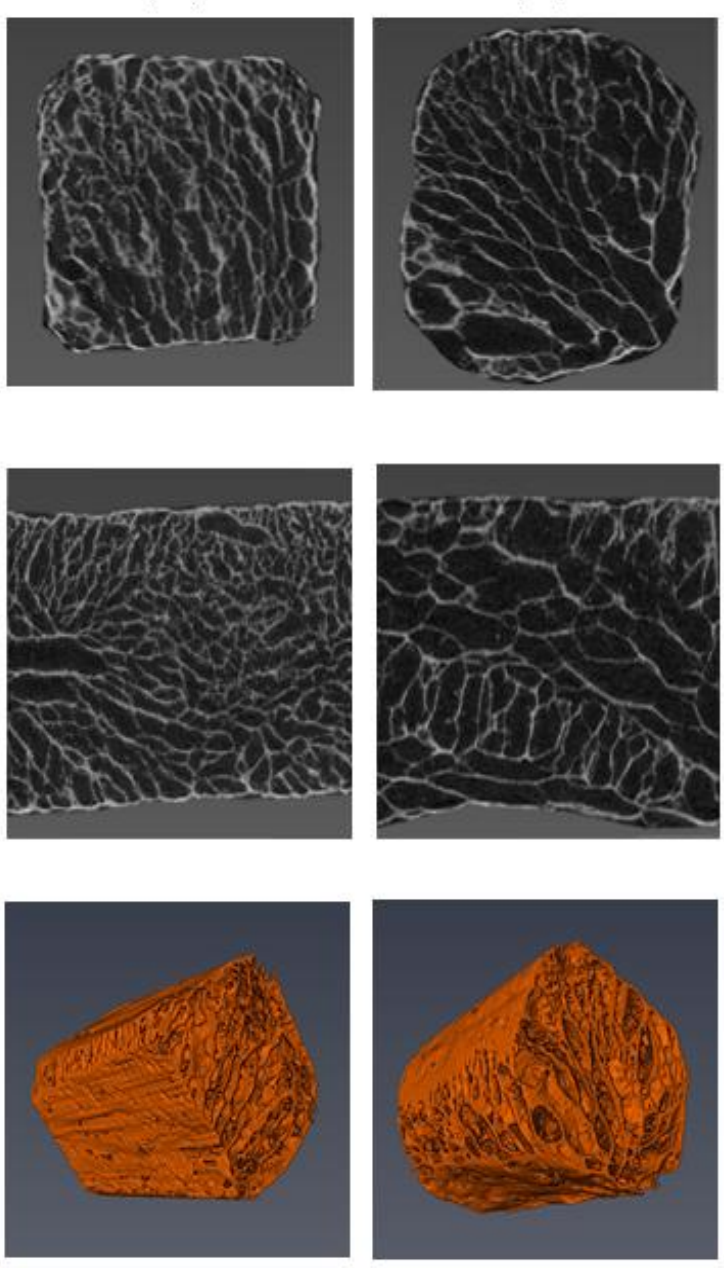

(S5)
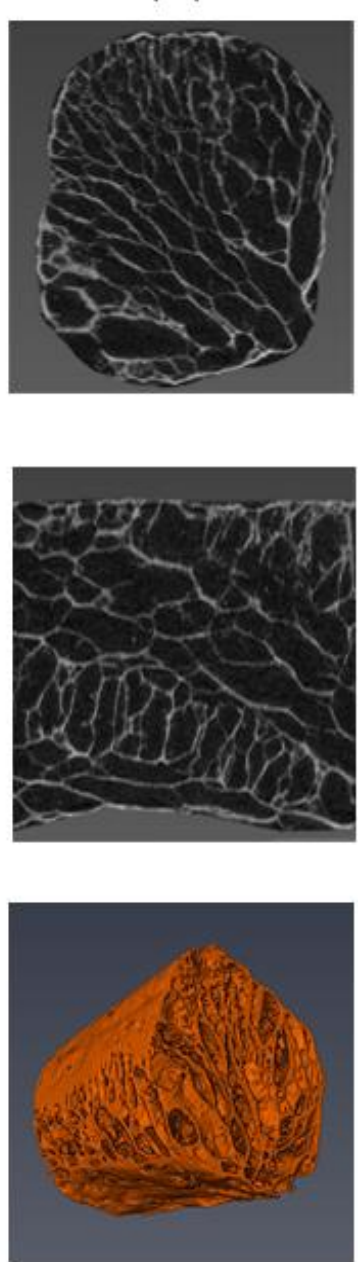

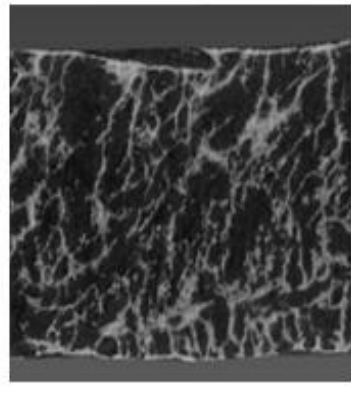

(S6)
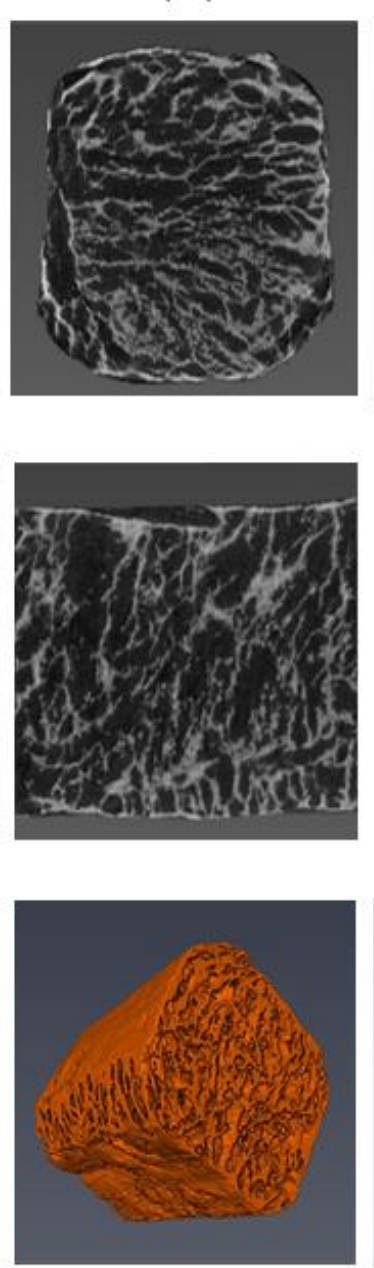

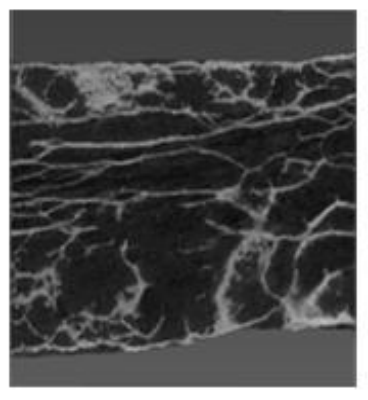

(S7)
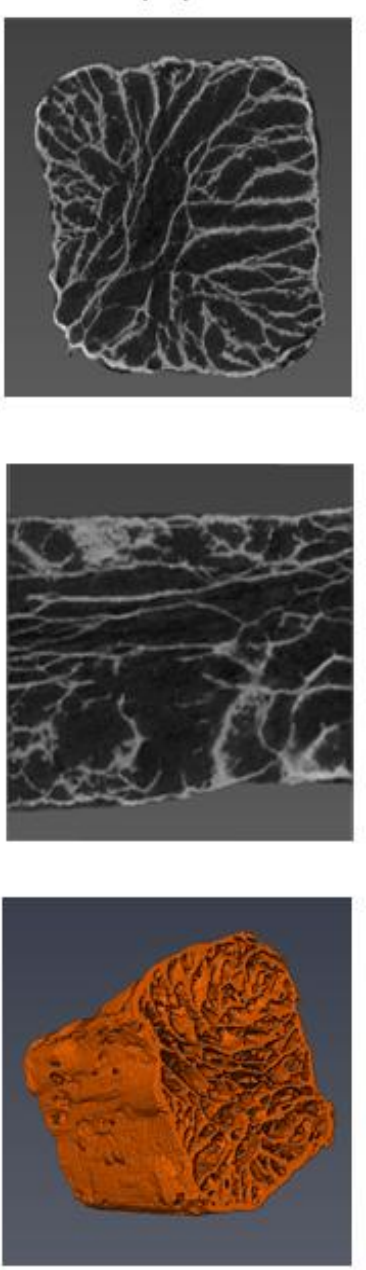

Figure 3 Masked grayscale orthoslices (xy plane and xz plane) and 3D images of potatoes frozen at different freezing conditions (S1S7). 


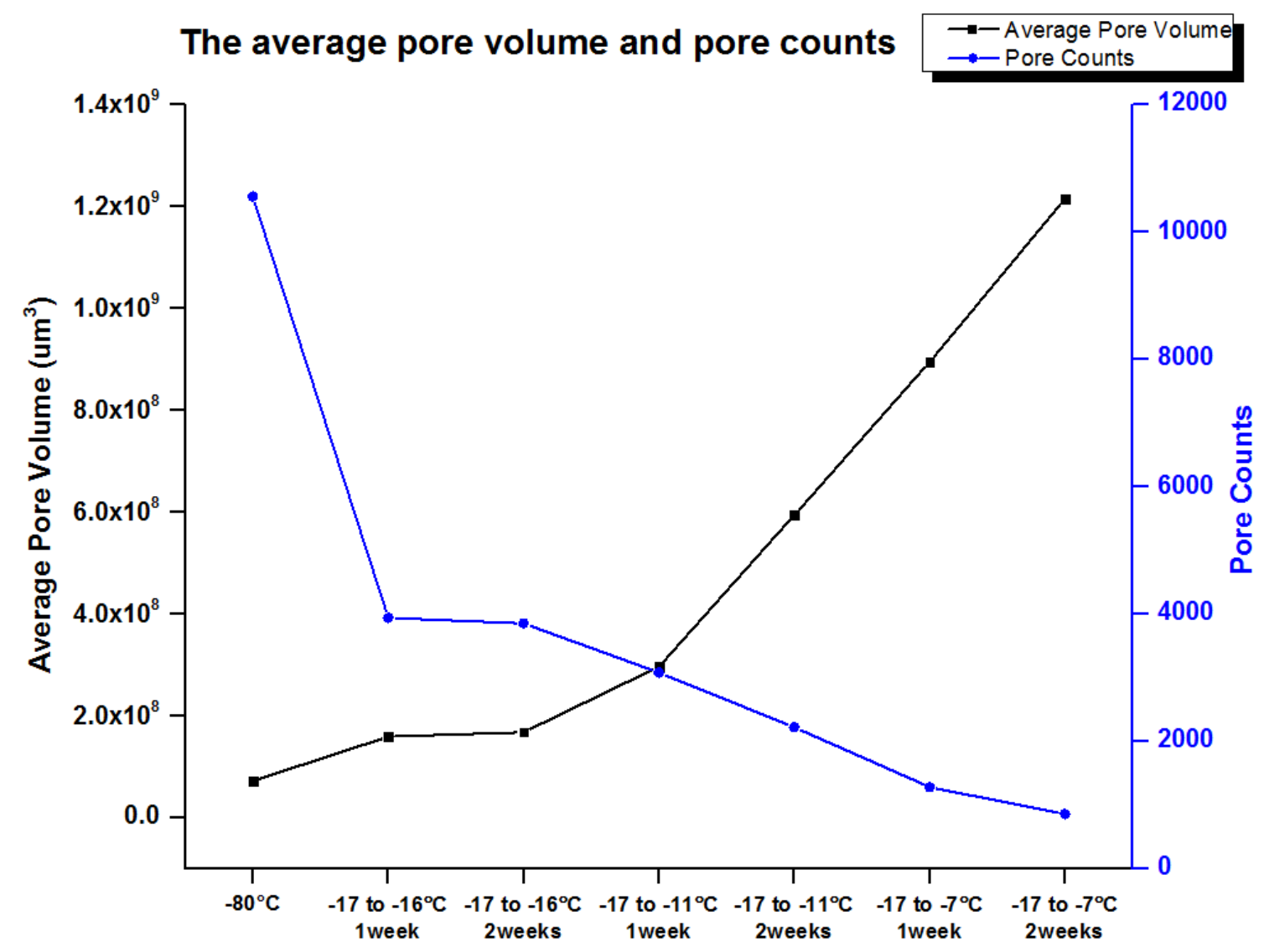

Figure 4 Average pore volume and numbers of pores for potatoes subjected to different freezing conditions. 


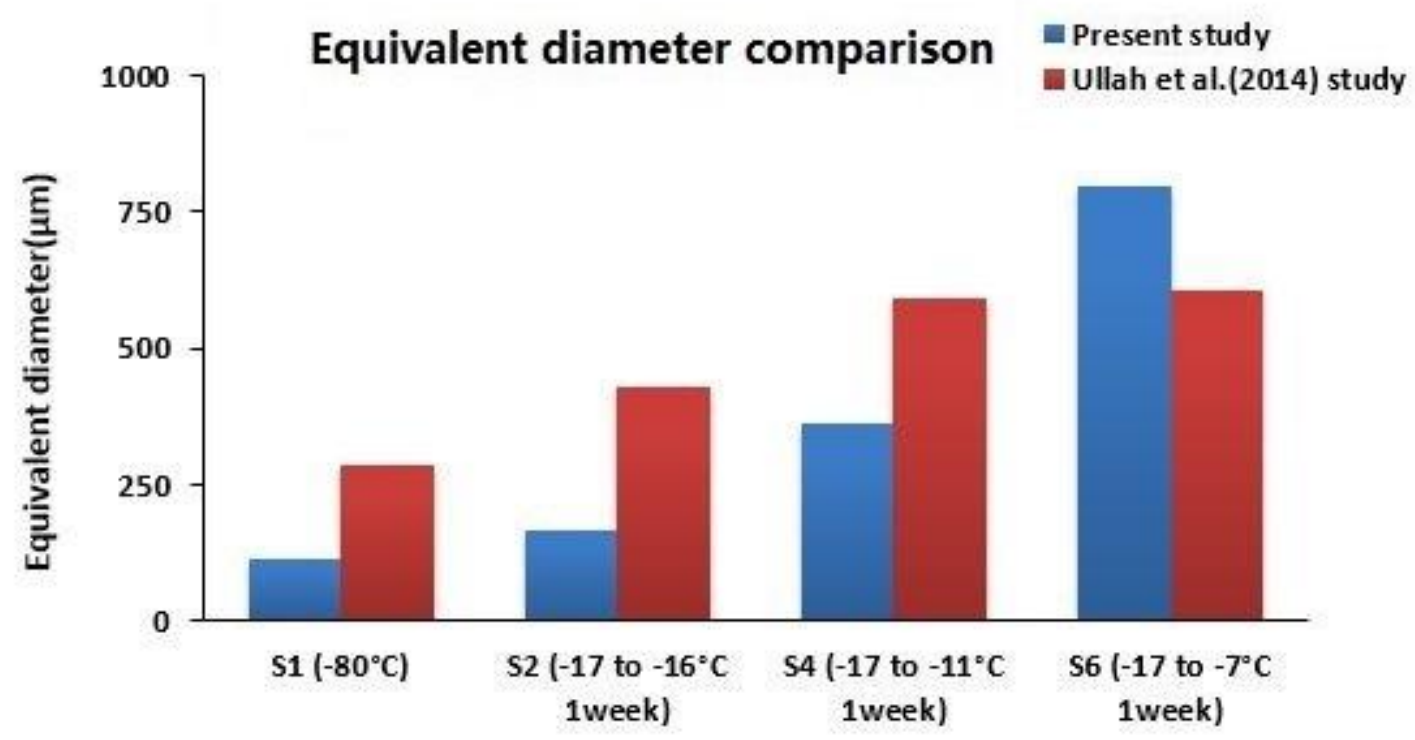

Figure 5 Equivalent diameter comparison of present study and Ullah et al. (2014) study. 


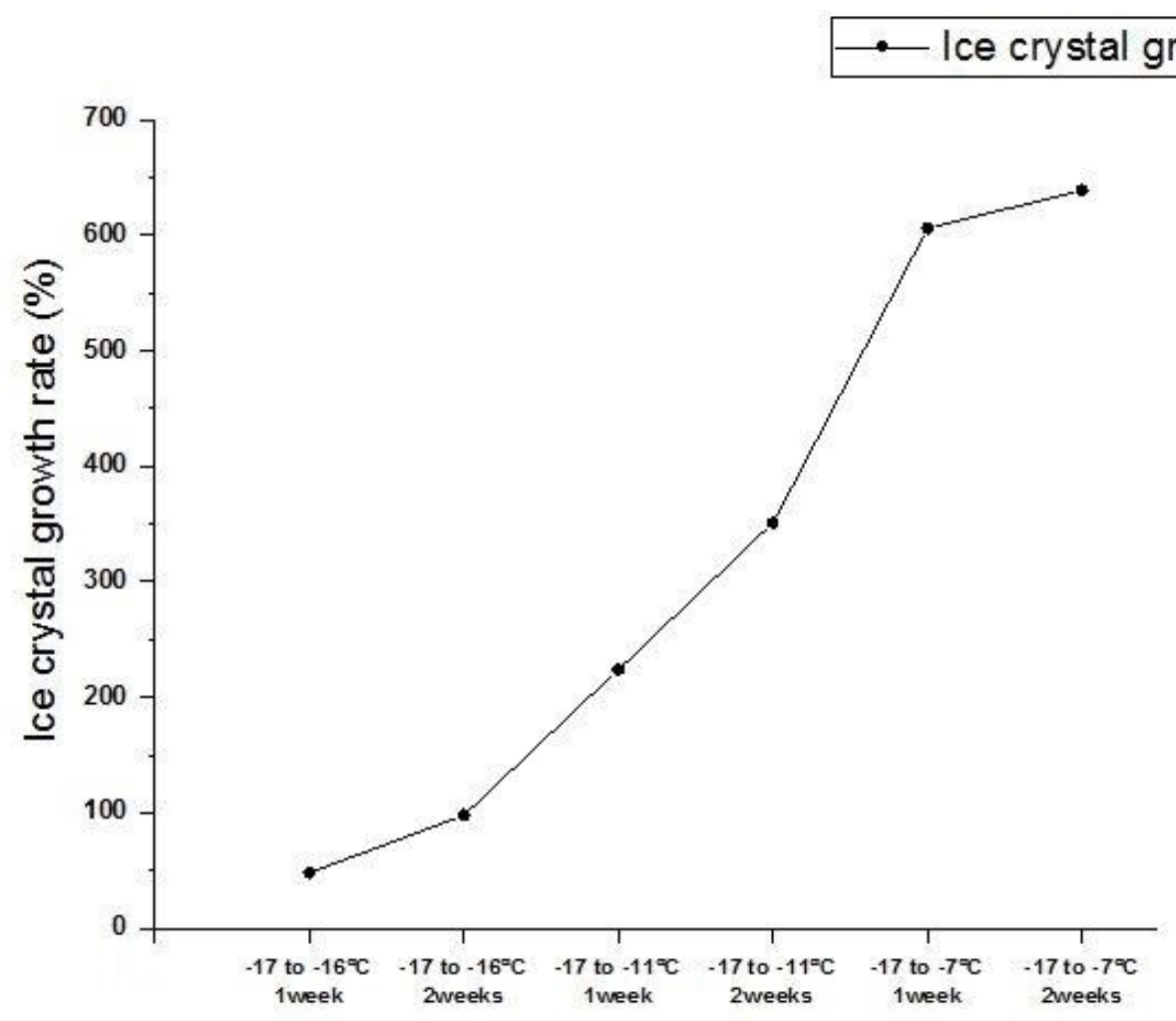

Figure 6 Ice crystal growth rate versus freezer temperature during storage of potatoes. 

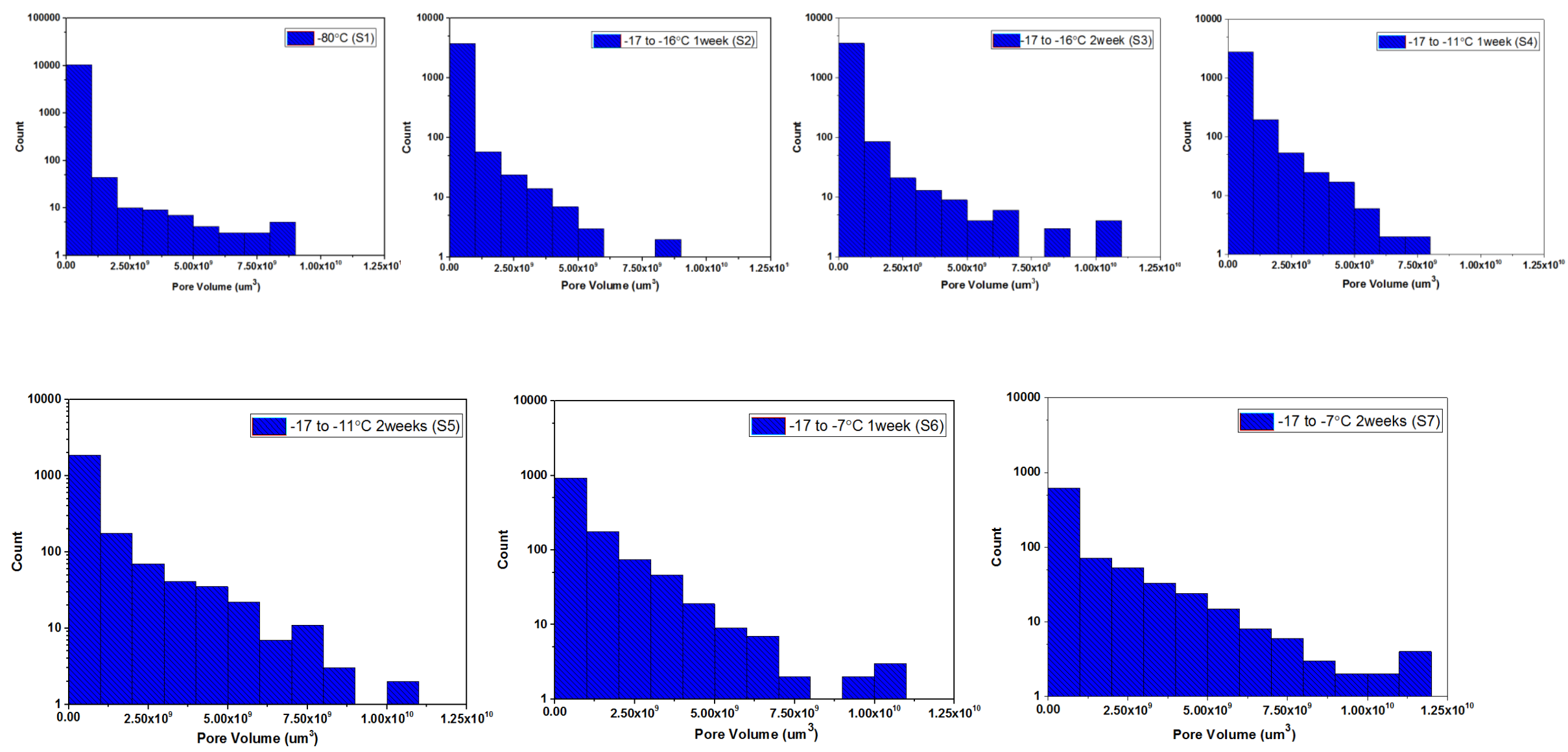

Figure 7 Pore size distribution (pore volume of pores) in potatoes subjected to different freezing conditions. The y-axis is plotted on $\log _{10}$ scale. 

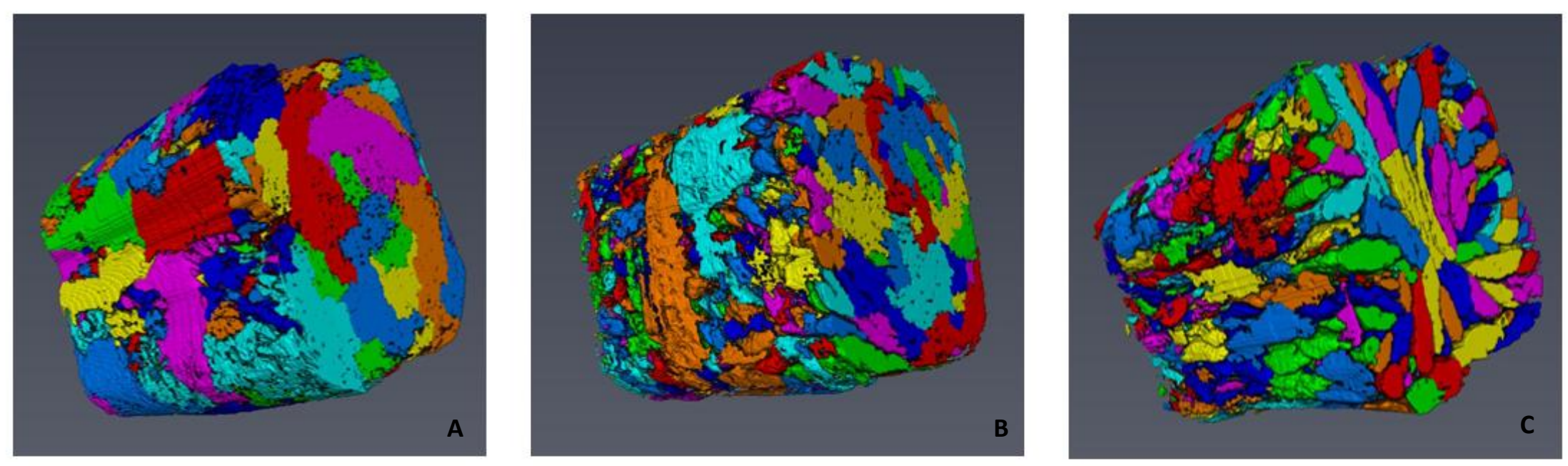

Figure 8 The 3D images of S1(A), S5(B) and S7(C) showing pores as a solid network (connected set of pores are labeled with the same color). 


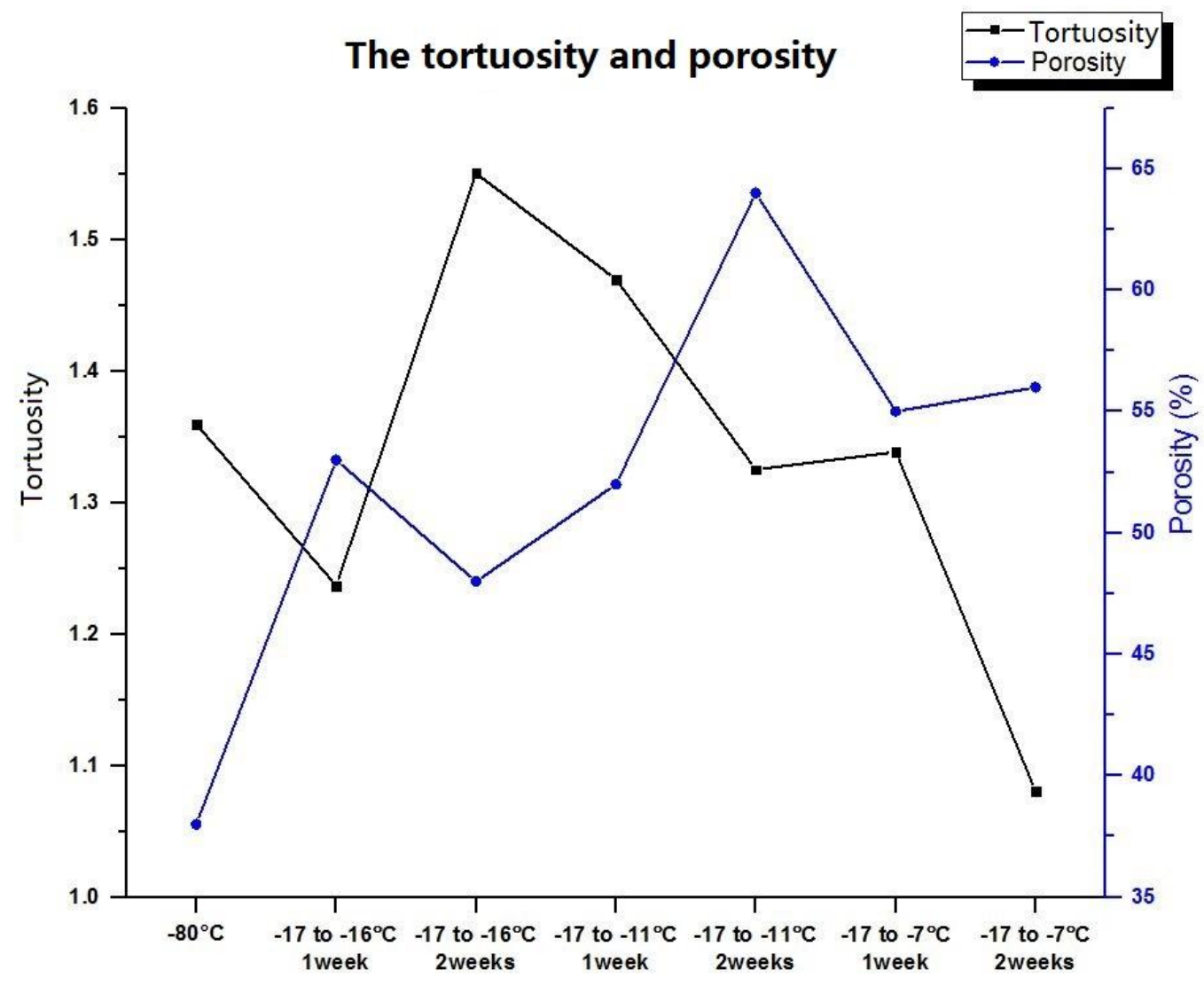

Figure 9 Tortuosity and porosity of potatoes subjected to different freezing conditions. 
Table 1 Comparasion of image analysis results in present study and Ullah's study.

\begin{tabular}{|c|c|c|c|c|c|c|}
\hline Present study & $\begin{array}{l}\text { Equivalent } \\
\text { diameter } \\
(\mu \mathrm{m})\end{array}$ & $\begin{array}{l}\text { Average } \\
\text { pore area } \\
\left(\mu \mathrm{m}^{2}\right)-\mathrm{A}_{3 \mathrm{D}}\end{array}$ & $\begin{array}{l}\text { Ice crystal } \\
\text { growth \% }\end{array}$ & Ullah study & $\begin{array}{l}\text { Equivalent } \\
\text { diameter } \\
(\mu \mathrm{m})\end{array}$ & $\begin{array}{l}\text { Ice crystal } \\
\text { growth \% }\end{array}$ \\
\hline $\mathrm{S} 1\left(-80^{\circ} \mathrm{C}\right)$ & 112.66 & $1.51 \times 10^{6}$ & & $-80^{\circ} \mathrm{C}$ & 284.34 & \\
\hline $\begin{array}{c}\mathrm{S} 2(-17 \text { to }- \\
\left.16{ }^{\circ} \mathrm{C} 1 \text { week }\right)\end{array}$ & 167.06 & $2.81 \times 10^{6}$ & $48 \%$ & -17 to $-16^{\circ} \mathrm{C}$ & 431.89 & $52 \%$ \\
\hline $\begin{array}{c}\mathrm{S} 3(-17 \text { to }- \\
\left.16^{\circ} \mathrm{C} 2 \text { weeks }\right)\end{array}$ & 223.35 & $2.97 \times 10^{6}$ & $98 \%$ & & & \\
\hline $\begin{array}{c}\mathrm{S} 4 \text { (-17 to - } \\
\left.11^{\circ} \mathrm{C} 1 \text { week }\right)\end{array}$ & 364.84 & $2.96 \times 10^{6}$ & $224 \%$ & -17 to $-11^{\circ} \mathrm{C}$ & 593.07 & $109 \%$ \\
\hline $\begin{array}{c}\mathrm{S} 5(-17 \text { to }- \\
\left.11^{\circ} \mathrm{C} 2 \text { weeks }\right)\end{array}$ & 508.01 & $4.14 \times 10^{6}$ & $351 \%$ & & & \\
\hline $\begin{array}{c}\mathrm{S} 6(-17 \text { to }- \\
\left.7^{\circ} \mathrm{C} 1 \text { week }\right)\end{array}$ & 795.88 & $9.07 \times 10^{6}$ & $606 \%$ & -17 to $-7^{\circ} \mathrm{C}$ & 605.03 & $113 \%$ \\
\hline $\begin{array}{c}\mathrm{S} 7(-17 \text { to }- \\
\left.7^{\circ} \mathrm{C} 2 \text { weeks }\right)\end{array}$ & 832.84 & $9.32 \times 10^{6}$ & $639 \%$ & & & \\
\hline
\end{tabular}

